\title{
Strategies for Prevention of ACL Injuries in Sportive Females
}

\author{
Francesco Manfreda*, JulienTeodori, Giuseppe Rinonapoli and Auro Caraffa \\ Department of Orthopedics and Traumatology, University of Perugia, Italy
}

Submission: February 4, 2017; Published: April 21, 2017

*Corresponding author: Francesco Manfreda, Department of Orthopedics and Traumatology, University of Perugia, Piazza dell'Università, 06123 Perugia, Italy, Email: francesco.manfreda@libero.it

Abstract

ACL injuries are extremely common in sportive people. Female gender presents a higher injury-rate for this kind of pathology because of biomechanics, anthropometrics and genetic features. Prevention of ACL-tear has made interest of research grow up. Through this paper we are trying to review the most important preventive principles for this type of injury. Several studies have been presented in the last years with the aim of validate successful preventive protocol. Anyway further research is needed in order to find a standardized program.

Keywords: Anterior cruciate ligament; Injury; Prevention; Female athletes; Sport injury prevention training program (SIPTP)

\section{Introduction}

In the last 40 years participation of women to sport has grown almost 10 times [1]. Currently, more than half of adolescent females are engaged in sports at school or clubs. In addition to an increased participation, young women have a higher incidence of knee injuries than male [2]. Furthermore, despite the ACL repair and correction of the instability, young women show an early onset of degenerative osteoarthritic changes [3].

The importance of prevention of ACL injuries without trauma is based on the following elements: ACL Injuries are the most common, with longer disability times and a devastating influence on the levels of patient activity and quality of life. Additionally the ACL Injuries have the highest economic cost among sport traumas [4]. Finally, knees with ACL deficiency have increased risk for secondary injuries such as meniscal tears and early development of osteoarthritis [5].

\section{Prevention of Risk-Factors and Reduction of Injury- Rate}

Maybe the proper knowledge of mechanism how the ACL is loaded, how it fails and of all the risk factors for ACL tears is the first approach for a preventive intervention [6]. As we know, biomechanical features [6], joint geometry [7], lower extremity alignment [8], body composition [9], genetic assessment [10] and hormonal patterns [11] could be important variables for female gender that may lead to an increase risk for tears. Some of these feature have been well studied and can be challenged, other ones are still in discussion and can be changed partially or not at all.

In these fields of study, only the neuromuscular and biomechanical risk factors have received adequate attention as regards prevention programs. These protocols are used to change the sport technique and improve the conditioning through the neuromuscular control, strength, plyometrics and balance training. Among all the components of the prevention program, plyometric training has proven to be one of the most effective tools to reduce ACL injuries without contact.

The plyometric component of prevention programs train the muscles, connective tissue, and nervous system to effectively carry out the stretch-shortening cycle and focus on proper technique and body mechanics. They are able to optimize the muscular activation and performance of lower limbs during jumping exercises. Electromyography for the evaluation of the preparatory and reactive work of medialis and lateralis vastus, posterior muscles, medial and lateral thigh and hip abductors and adductors shows an increase of the preparatory adductor activity and cooperation adductor-abductor during jumpstop [12]. These data strongly support the role of strategies of activation of the hip muscles for control of dynamic alignment of the lower limbs in landing.

The neuromuscular training has been shown to be able to make a significant improvement in the total stability of the single limb and the anterior-posterior stability (sagittal plane), but not 
the medial-lateral stability (in the coronal plane). Furthermore, this improvement involves the total postural stability [13]. Among other beneficial effects of neuromuscular training in female athletes, an increased angle of knee flexion during landing from a vertical jump and a decreased torsion of valgus and varus knee should be improved; in fact these elements are well-known risk factors for ACL injuries in female gender [14]. Exercises "on the playground" are extremely important, requiring knee and hip flexion in landing and lateral movements, avoiding the excessive knee valgus in landing and squat exercise, increasing core strength, hamstrings, gluteus medius, hip abductors and techniques for addressing proper deceleration [15].

The kinematics of the hip and knee are considered important elements for the prevention of the risk of injury in women. In particular, training for proper kinematics of the hip and knee, during a landing exercise, seems to lead to a significantly lower internal rotation and greater angles of hip abduction during the landing gesture [16]. The "high risk" athletes that play a regular neuromuscular training have a lower knee-moment of abduction of $13 \%$ [17].

Training focused on hamstrings and on the relationship between power of quadriceps and hamstrings have shown an increase in the functional relationship (ratio: eccentric activity of hamstring and concentric activity of quadriceps) [18]. This object is specifically recommended for the prevention of ACL injuries [19].

In the jump, the angle moment of dynamic valgus knee, which is of high prevalence in the female gender, during the stop-jump support is decrease by neuromuscular training; the maximum knee flexion angles are increased during the stance phase of the jumps [20]. The anticipation of the external forces and the loads in order to stabilize the joint and protecting adjacent structures has revealed a decrease of the incidence of ACL injury up to 74\% [21].

Finally, in prevention programs, the correct sport-specific movement is the most important element. The reduction of highrisk gestures can lead to a $41 \%$ reduction of LCA ruptures [22]. Programs that focus on correcting individualized techniques could be considered the best ones. [23]. For example, expert modeling that are combined with self-modeling are the most effective way to change risk mechanisms as landing biomechanics [24].

"The American Journal of Sports Medicine" in 2009, through an experimental study has drawn up a training program with the intention to emphasize the prevention of biomechanical risk factors. This protocol, whose name is "sport injury prevention training program" (SIPTP), still well-known and approved, has the target to improve muscle strength, flexibility and biomechanical properties (Table 1). Kinetic and kinematic outcomes such as the height of the jump, the maximum of the knee bending angle, the minimum distance between the two knees, the maximum angle of internal rotation of the knee, the maximum moment of knee extension and the moment of maximum valgus knee were evaluated. Results reported greater knee flexion angles, a greater distance between knees and optimization of the HamstringsQuadriceps (H-Q) ratio [25].

Table 1: sport injury prevention training program [25].

\begin{tabular}{|c|c|}
\hline Exercise & Specific Exercises \\
\hline Warm-up & Jog line to line \\
Shuttle run \\
Backward running
\end{tabular}

An interesting thing is that training programs of force show no significant difference in the kinematics and kinetics of the knee and hip. The training of force alone does not improve the kinematics and kinetics of the knee and hip in amateur athletes. Therefore, only strength interventions may be not sufficient to reduce the risk of ACL injuries in female players. So it seems that the one-component prevention programs have no significant impact on the biomechanical risk factors in female athletes [26].

\section{Conclusion}

Preventing non-contact ACL injuries is a high relevance in sports traumatology. Although well-controlled ACL injuryprevention programs seem to be able to reduce the incidence of ACL injuries, to date there is no standardized intervention protocol. Currently, sex differences that lead to a higher rate of injury in female are object of several studies. Most of these 
studies emphasize training for reducing biomechanical and neuromuscular risk factors. Maybe further interventions should be applied. The ideal preventive program should be further identified.

\section{References}

1. Wushanley Y (2004) Playing Nice and Losing: The Struggle for Control of Women's Intercollegiate Athletics, 1960-2000. Syracuse University Press, USA.

2. Peck KY, Johnston DA, Owens BD, Cameron, KL (2013) The Incidence of Injury Among Male and Female Intercollegiate Rugby Players. Sports Health 5(4): 327-333.

3. Amoako AO, Pujalte GGA (2014) Osteoarthritis in Young, Active, and Athletic Individuals. Clin Med Insights Arthritis Muscul Disodr 7: 2732.

4. Kiapour AM, Murray MM (2014) Basic science of anterior cruciate ligament injury and repair. Bone Joint Res 3(2): 20-31.

5. Simon D, Mascarenhas R, Saltzman BM, Rollins M, Bach BR, et al. (2015) The Relationship between Anterior Cruciate Ligament Injury and Osteoarthritis of the Knee. Advances in Orthopedics, 2015(2015): $1-11$.

6. Shultz SJ, Schmitz RJ, Benjaminse A, Collins M, Ford K, et al. (2015) ACL Research Retreat VII: An Update on Anterior Cruciate Ligament Injury Risk Factor Identification, Screening and Prevention. J Athl Train 50(10): 1076-1093.

7. Whitney DC, Sturnick DR, Vacek PM, Slauterbeck JR, Hashemi J, et al. (2014) Relationship between the risk of suffering a first-time noncontact ACL injury geometry of the femoral notch and ACL: A prospective cohort study with a nested case-control analysis. Am J Sports Med 42(8): 1796-1805.

8. Nguyen AD, Shultz SJ (2007) Sex differences in lower extremity posture. J Orthop Sports Phys Ther 37(7): 389-398.

9. Montgomery MM, Shultz SJ, Schmitz RJ (2014) The effect of equalizing landing task demands on sex differences in lower extremity energy absorption. Clin Biomech Bristol Avon 29(7): 760-766.

10. O'Connell K, Knight H, Ficek K, Leonska DA, Maciejewska KA, et al. (2015) Interactions between collagen gene variants and risk of anterior cruciate ligament rupture. Eur J Sport Sci 15(4): 341-350.

11. Shultz SJ, Schmitz RJ, Beynnon BD (2011) Variations in varus/valgus and internal/external rotational knee laxity and stiffness across the menstrual cycle. J Orthop Res 29(3): 318-325.

12. Chimera NJ, Swanik KA, Swanik CB, Straub SJ (2004) Effects of plyometric training on muscle-activation strategies and performance in female athletes. J Athl Train 39(1): 24-31.

13. Paterno MV, Myer GD, Ford KR, Hewett TE (2004) Neuromuscular training improves single-limb stability in young female athletes. J Orthop Sports Phys Ther 34(6): 305-316.

This work is licensed under Creative Commons Attribution 4.0 Licens DOI: 10.19080/JOJCS.2017.02.555593
14. Myer GD, Ford KR, Palumbo JP, Hewett TE (2008) Neuromuscular training improves performance and lower extremity biomechanics in female athletes. J Strength Cond Res 19(1): 51-60.

15. Codorean H, Codorean IB, Cojocaru V (2016) Functional rehabilitation of the knee joint after cruciate ligament reconstruction in the football players - recovery in therapy room. Medicin a Sportiva. Journal of Roman Sports Medcn Society 12(2): 2792-2797.

16. Pollard CD, Sigward SM, Ota S, Langford K, Powers CM (2006) The influence of in-season injury prevention training on lower-extremity kinematics during landing in female soccer players. Clin J Sport Med 16(3): 223-227.

17. Myer GD, Ford KR, Brent JL, Hewett TE (2007) Differential neuromuscular training effects on ACL injury risk factors in high-risk versus 'low-risk athletes. BMC Musculoskelet Disord 8: 39.

18. Holcomb WR, Rubley MD, Lee HJ, Guadagnoli MA (2007) Effect of hamstring-emphasized resistance training on hamstring: quadriceps strength ratios. J Strength Cond Res 21: 41-47.

19. Caraffa A, Antinolfi P, Rinonapoli G, Manfreda F (2016) EBM: VALUTAZIONE DELLO SPORTIVO. In: Zaffagnini \& Vascellari A (eds.), IL RITORNO ALLO SPORT, CIC Edizioni Internazionali, pp. 191- 206.

20. Chappell JD, Limpisvasti $O$ (2008) Effect of a neuromuscular training program on the kinetics and kinematics of jumping tasks. Am J Sports Med 36(6): 1081-1086.

21. Mandelbaum BR, Silvers HJ, Watanabe DS, Knarr JF, Thomas SD, et al. (2005) Effectiveness of a neuromuscular and proprioceptive training program in preventing anterior cruciate ligament injuries in female athletes: 2-year follow up. Am J Sports Med 33(7): 1003-1010.

22. Gilchrist J, Mandelbaum BR, Melancon H, Ryan GW, Silvers HJ, et al. (2008) A randomized controlled trial to prevent non-contact anterior cruciate ligament injury in female collegiate soccer players. Am J Sports Med 36 (8): 1476-1483.

23. Gokeler A, Welling W, Otten B, Benjaminse A (2015) Enhanced retention of drop vertical jump landing strategies assessed with the Landing Error Scoring System. J Athl Train 50(10): 1110.

24. Munro A, Herrington L (2014) The effect of videotape augmented feedback on drop jump landing strategy: implications for anterior cruciate ligament and patellofemoral joint injury prevention. Knee 21(5): 891-895.

25. Lim BO, Lee YS, Kim JG, An KO, Yoo J, et al. (2009) Effects of sports injury prevention training on the biomechanical risk factors of anterior cruciate ligament injury in high school female basketball players. Am J Sports Med 37 (9): 1728-1734.

26. Herman DC, Weinhold PS, Guskiewicz KM, Garrett WE, Yu B, et al. (2008) The effects of strength training on the lower extremity biomechanics of female recreational athletes during a stop-jump task. Am J Sports Med 36(4): 733-740.

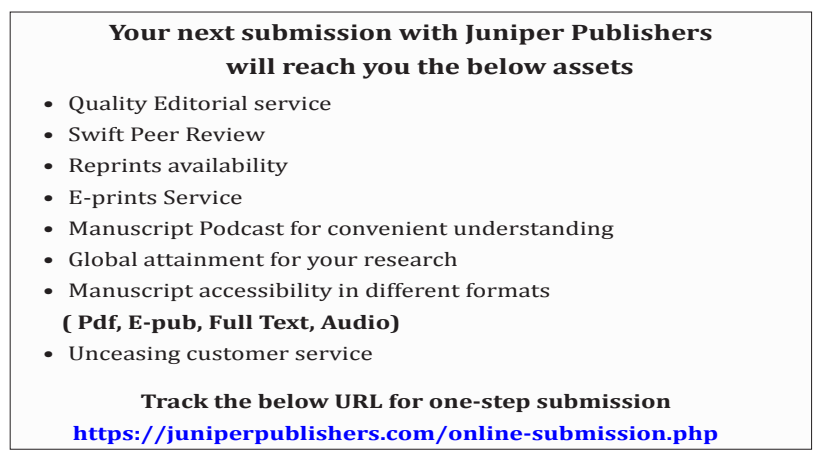

